\title{
Monolayers of a novel ionoselective butadienyl dye
}

\author{
T.I. Sergeeva, ${ }^{\text {a }}$ S.Yu. Zaitsev, ${ }^{\text {a,b }}$ M.S. Tsarkova, ${ }^{b}$ S.P. Gromov, ${ }^{c}$ A.I. Vedernikov, ${ }^{c}$ \\ M.S. Kapichnikova, ${ }^{c}$ M.V. Alfimov, ${ }^{c}$ T.S. Druzhinina, ${ }^{d}$ and D. Möbius ${ }^{d, *}$ \\ ${ }^{a}$ Institute of Bioorganic Chemistry, Russian Academy of Sciences, Miklucho-Maklaya Str. 16/10, Moscow 117871, Russia \\ ${ }^{\mathrm{b}}$ Moscow State Academy of Veterinary Medicine and Biotechnology, Acad. Skryabina Str. 23, Moscow 117871, Russia \\ ${ }^{\mathrm{c}}$ Center Photochemistry, Russian Academy of Sciences, Novatorov Str. 7a, Moscow 117334, Russia \\ d Max-Planck-Institut für biophysikalische Chemie, D-37070 Göttingen, Germany \\ Received 20 August 2002; accepted 2 January 2003
}

\begin{abstract}
The novel amphiphilic benzodithia-18-crown-6 butadienyl dye (1) forms relatively stable insoluble monolayers on distilled water (collapse pressure of $41 \mathrm{mN} / \mathrm{m}$ ) and on aqueous subphases containing alkali metal or heavy metal salts (collapse pressures in the range of 27-38 $\mathrm{mN} / \mathrm{m}$, respectively). The dye $\mathbf{1}$ monolayer organization depends on chromophore association and interactions (especially complex formation) with heavy and alkali metal ions as deduced from surface pressure-area and surface potential-area isotherms as well as reflection spectra and Brewster angle microscopy observations. Dye 1 undergoes specific interactions with $\mathrm{Hg}^{2+}$ and $\mathrm{Ag}^{+}$, respectively (formation of different complexes). Nonspecific interactions have been observed with other salts, such as $\mathrm{KClO}_{4}$ or $\mathrm{Pb}\left(\mathrm{ClO}_{4}\right)_{2}$. Further, dye 1 monolayers on 1 mM $\mathrm{Hg}\left(\mathrm{ClO}_{4}\right)_{2}$ solution undergo reversible photoisomerization, in contrast to monolayers on water and other aqueous salt subphases.

(c) 2003 Elsevier Inc. All rights reserved.
\end{abstract}

Keywords: Monolayers; Crown ethers; Butadienyl dye; Ionoselectivity; Photosensitivity

\section{Introduction}

Monolayers of various crown ethers can serve as unique models for the investigation of molecular recognition and interaction phenomena at interfaces that can be considered as fundamental features of biological membranes. Modification of the crown ethers with long hydrocarbon chains and photosensitive groups leads to functional surface-active derivatives, which are particularly useful for the construction of various supramolecular systems [1]. These systems are also promising for future applications as sensitive components for ion detection in optical and electrochemical devices, as novel materials for recording, storage and processing of optical information, as components in optical waveguides, and for photocontrolled extraction of metal cations [2].

After our first publication devoted to the investigation of monolayers and Langmuir-Blodgett (LB) films of crown ethers [3], the literature in this field was summarized in the well-known review of Lednev and Petty [4]. During last years, attention has been devoted to the study of monolay-

\footnotetext{
* Corresponding author.

E-mail address: dmoebiu@gwdg.de (D. Möbius).
}

ers at the air-water interface and transferred onto solid substrates of photo- and electroactive amphiphilic crown ethers with azobenzene groups in the macrocycle [5-8]. In contrast to this type of amphiphilic compounds, we are studying amphiphilic crown ethers with $-\mathrm{C}=\mathrm{C}$ - group as a part of the chromophore attached to the macrocycle. Our recent studies [9-14] on monolayers and LB films of a series of amphiphilic crown ether styryl dyes with variable size of the polyether ring and varying substitution in the chromophoric part demonstrated the possibility of preparing photosensitive films with the ability to selectively bind particular alkali and heavy metal cations. Recently, analogous compounds with butadienyl instead of styryl moiety in the photosensitive part have been synthesized. Here, we report on the ionoselective and photosensitive properties of such a novel amphiphilic benzodithia-18-crown-6 butadienyl dye in monolayers.

\section{Experimental}

\subsection{Materials}

The novel amphiphilic benzodithia-18-crown-6 butadienyl dye (1) has been prepared by the condensation re- 
action of 2-methyl-3-octadecyl-benzothiazolium perchlorate with dithia-18-crown-6 ether cinnamaldehyde in anhydrous ethanol:

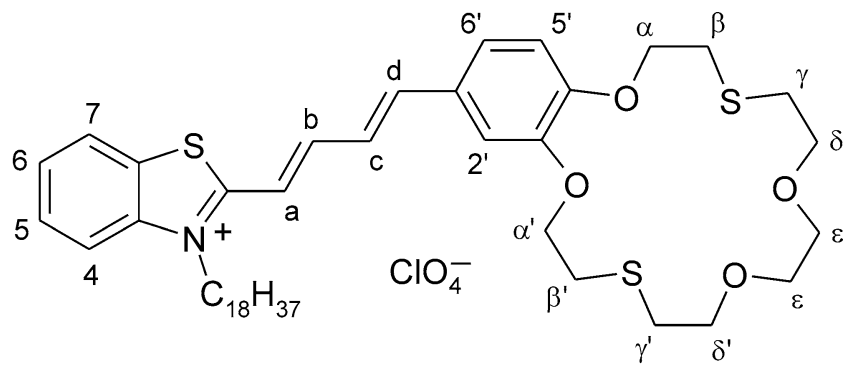

1

The synthesis of the initial heterocyclic salt [15] and crown ether cinnamaldehyde [16] has been described earlier. Compound $\mathbf{1}$ has been thoroughly characterized by NMR spectroscopy and elemental analysis. According to NMR spectra the dye 1 has been obtained in the trans,transconfiguration $\left({ }^{3} J_{\mathrm{H}(\mathrm{a}), \mathrm{H}(\mathrm{b})}\right.$ and $\left.{ }^{3} J_{\mathrm{H}(\mathrm{c}), \mathrm{H}(\mathrm{d})}=14.4-15.3 \mathrm{~Hz}\right)$ and the $s$-trans-conformation $\left({ }^{3} J_{\mathrm{H}(\mathrm{b}), \mathrm{H}(\mathrm{c})}=11.1 \mathrm{~Hz}\right)$. M.p. $=179-181{ }^{\circ} \mathrm{C} \cdot \mathrm{H}^{1} \mathrm{NMR}$ (Bruker DRX500 spectrometer, $\left.\mathrm{CDCl}_{3}\right) \delta: 0.88\left(\mathrm{t}, 3 \mathrm{H}, \mathrm{CH}_{3}\right) ; 1.26\left(\mathrm{~m}, 28 \mathrm{H}, 14 \mathrm{CH}_{2}\right) ; 1.46$ $\left(\mathrm{m}, 2 \mathrm{H}, \mathrm{CH}_{2} \mathrm{CH}_{2} \mathrm{CH}_{2} \mathrm{~N}\right) ; 1.86\left(\mathrm{~m}, 2 \mathrm{H}, \mathrm{CH}_{2} \mathrm{CH}_{2} \mathrm{~N}\right) ; 2.90$ $\left(\mathrm{m}, 2 \mathrm{H}, \gamma^{\prime}-\mathrm{CH}_{2} \mathrm{~S}\right) ; 3.08\left(\mathrm{~m}, 2 \mathrm{H}, \beta^{\prime}-\mathrm{CH}_{2} \mathrm{~S}\right) ; 3.10(\mathrm{~m}, 2 \mathrm{H}$, $\left.\gamma-\mathrm{CH}_{2} \mathrm{~S}\right) ; 3.19\left(\mathrm{~m}, 2 \mathrm{H}, \beta-\mathrm{CH}_{2} \mathrm{~S}\right) ; 3.65\left(\mathrm{~m}, 4 \mathrm{H}, 2 \varepsilon-\mathrm{CH}_{2} \mathrm{O}\right)$; $3.73\left(\mathrm{~m}, 2 \mathrm{H}, \delta-\mathrm{CH}_{2} \mathrm{O}\right) ; 3.82\left(\mathrm{~m}, 2 \mathrm{H}, \delta^{\prime}-\mathrm{CH}_{2} \mathrm{O}\right) ; 4.02(\mathrm{~m}$, $\left.2 \mathrm{H}, \alpha-\mathrm{CH}_{2} \mathrm{O}\right) ; 4.29\left(\mathrm{~m}, 2 \mathrm{H}, \alpha^{\prime}-\mathrm{CH}_{2} \mathrm{O}\right) ; 4.59\left(\mathrm{~m}, 2 \mathrm{H}, \mathrm{CH}_{2} \mathrm{~N}\right)$; $6.51\left(\mathrm{~d}, 1 \mathrm{H}, \mathrm{H}\left(5^{\prime}\right), J\right.$ 8.2); 6.94 (d, 1H, $\mathrm{H}\left(6^{\prime}\right), J$ 8.2); 7.13 (s, $\left.1 \mathrm{H}, \mathrm{H}\left(2^{\prime}\right)\right) ; 7.23$ (d, 1H, H(d), J 15.3); 7.44 (dd, 1H, H(c), $J$ 11.1, $J$ 15.3); $7.46(\mathrm{~d}, 1 \mathrm{H}, \mathrm{H}(\mathrm{a}), J$ 14.4); 7.59 (d, $1 \mathrm{H}$, $\mathrm{H}(4), J$ 8.4); 7.63 (m, 1H, H(6)); 7.70 (m, 1H, H(5)); 7.88 (dd, 1H, H(b), J 11.1, J 14.4); 7.95 (d, 1H, H(7), J 7.9). Anal. Calculated for $\mathrm{C}_{45} \mathrm{H}_{68} \mathrm{ClNO}_{8} \mathrm{~S}_{3}$ (881.5); C, 61.23; H, 7.77; N, 1.59. Found: C, 61.46; H, 7.84; N, 1.58.

The salts $\mathrm{KClO}_{4}(99+\%), \mathrm{AgClO}_{4}(99.9 \%), \mathrm{Hg}\left(\mathrm{ClO}_{4}\right)_{2}$ (98\%) and $\mathrm{Pb}\left(\mathrm{ClO}_{4}\right)_{2}(99.995 \%)$ have been purchased from Aldrich and were used without further purification. The water has been cleaned with a Milli-Q filtration unit of Millipore Corp. (specific resistance $18 \mathrm{M} \Omega \mathrm{cm}$, surface tension $72.7 \mathrm{mN} / \mathrm{m}$ at $20^{\circ} \mathrm{C}$ ).

\subsection{Methods}

Surface pressure $(\pi)$-molecular area $(A)$ and surface potential $(\Delta V)$-molecular area $(A)$ isotherms of dye monolayers have been recorded on a rectangular trough (dimensions $11 \times 38 \times 0.8 \mathrm{~cm}$ ) made from polytetrafluoroethylene provided with a 2 -cm-wide filter paper Wilhelmy balance and vibrating plate condenser (with Pt plate, diameter $1.5 \mathrm{~cm}$, operating at $400 \mathrm{~Hz}$ ). The $1 \mathrm{mM}$ dye solution $(35 \mu \mathrm{l})$ has been spread onto water or various $1 \mathrm{mM}$ aqueous salt solutions $\left(20^{\circ} \mathrm{C}\right)$, and the monolayers have been compressed by moving the barrier with a constant speed of about $16.1 \mathrm{~cm}^{2} / \mathrm{min}$.
The dye monolayers have been characterized by Brewster angle microscopy (BAM) [17] using a MiniBAM (NFT Göttingen) equipped with a laser diode, emission wavelength $660 \mathrm{~nm}$. Reflection spectra as well as temporal variations of reflectivity of monolayers at constant surface pressure have been measured under normal incidence of light with a modified spectrometer of the type described earlier [18] and are plotted as the difference $\Delta R$ of the reflectivities of the monolayer-covered surface and the bare surface.

\section{Results and discussion}

\subsection{Surface pressure-area and surface potential-area isotherms}

The amphiphilic benzodithia-18-crown- 6 butadienyl dye forms relatively stable insoluble monolayers on distilled water and various aqueous salt subphases. The collapse pressure of the dye monolayers, according to $\pi-A$ isotherms and BAM observations, is about $41 \mathrm{mN} / \mathrm{m}$ on distilled water that is higher than obtained for monolayers of benzo18-crown-6 styryl dye $(25.5 \mathrm{mN} / \mathrm{m})$ or benzo-15-crown5 styryl dye $(34.5 \mathrm{mN} / \mathrm{m})$, respectively [13]. The $\pi-A$ isotherms of the dye on water and aqueous solutions of $\mathrm{KClO}_{4}, \mathrm{~Pb}\left(\mathrm{ClO}_{4}\right)_{2}$ and $\mathrm{Hg}\left(\mathrm{ClO}_{4}\right)_{2}$, concentration $1 \mathrm{mM}$, are
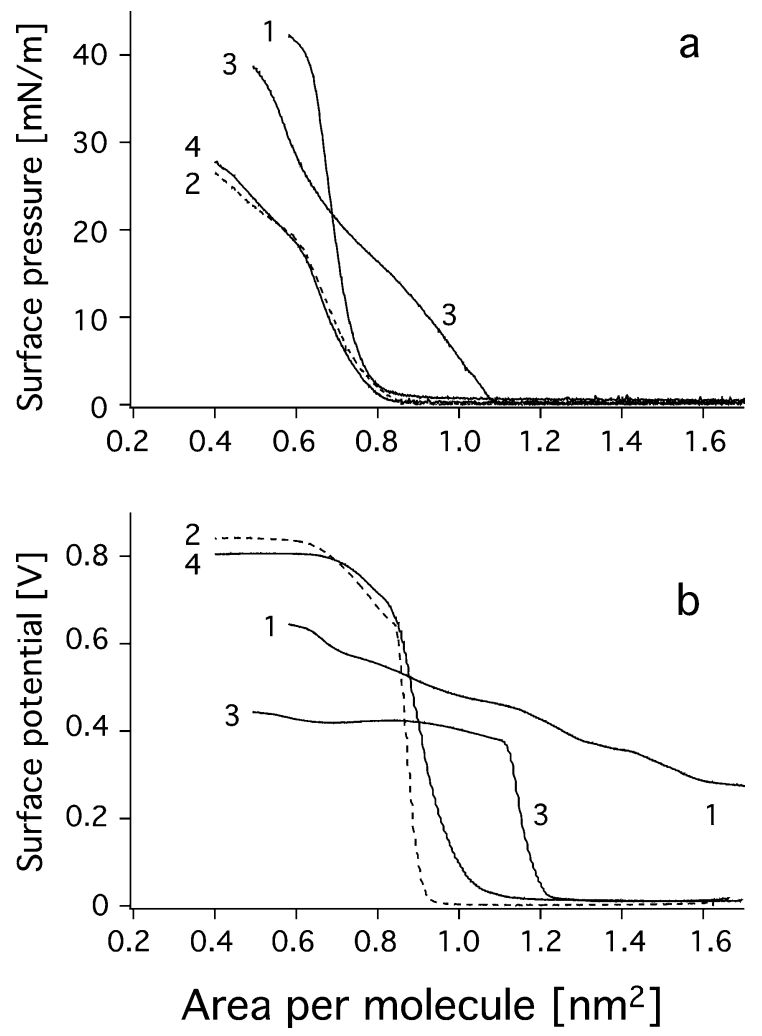

Fig. 1. Surface pressure-area isotherms (a) and surface potential-area isotherms (b) of the crown-ether dye $\mathbf{1}$ monolayers on water (1) and $1 \mathrm{mM}$ aqueous solutions of $\mathrm{KClO}_{4}$ (dashed, 2), $\mathrm{Hg}\left(\mathrm{ClO}_{4}\right)_{2}$ (3), and $\mathrm{Pb}\left(\mathrm{ClO}_{4}\right)_{2}$ (4) at $20^{\circ} \mathrm{C}$. 
shown in Fig. 1a, and the corresponding $\Delta V-A$ isotherms in Fig. 1b. There are remarkable differences in both types of dye isotherms by subphase variations, illustrating the effects of specific and nonspecific dye-ion interactions as well as chromophore organization.

The comparison of the dye $\pi-A$ isotherms on water (Fig. 1a, curve 1) and $1 \mathrm{mM} \mathrm{KClO}_{4}$ (Fig. 1a, dashed curve 2) shows a pronounced contraction in the presence of $\mathrm{KClO}_{4}$. Since no complex formation of the macrocycle with $\mathrm{K}^{+}$has been found in solution, the differences are attributed to nonspecific interaction of the cationic dye 1 with the anion. A pronounced influence of anions in the aqueous subphase on monolayer organization of a cationic amphiphile, as expressed in $\pi-A$ and $\Delta V-A$ isotherms as well as topography, has been observed in the case of dimethyldioctadecylammonium bromide [19]. Our interpretation here is supported by the high similarity of the $\pi-A$ isotherm of the monolayer on $1 \mathrm{mM} \mathrm{HClO}_{4}$ (data not shown here). Further, the $\pi-A$ isotherm in the presence of $\mathrm{Pb}\left(\mathrm{ClO}_{4}\right)_{2}$ (Fig. 1a, curve 4) closely resembles that measured in the presence of $\mathrm{KClO}_{4}$ (Fig. 1a, dashed curve 2), and this applies also for the hysteresis behavior upon expansion of the compressed monolayer (data not shown here) as well as for the monolayer topography characterized by BAM (see later). Therefore, monolayer organization is similar in these three cases, excluding noticeable complex formation of $\mathbf{1}$ with $\mathrm{Pb}^{2+}$ ions in the subphase. This is rather surprising for a macrocycle with two $\mathrm{S}$ atoms that should strongly interact with $\mathrm{Pb}^{2+}$. Indeed, complex formation is clearly observed spectroscopically in acetonitrile solution.

In the case of $\mathrm{Hg}\left(\mathrm{ClO}_{4}\right)_{2}$ salt, the dye monolayer has two states (liquid-expanded state I between $\pi=0$ and $20 \mathrm{mN} / \mathrm{m}$, i.e., $A=1.1$ to $0.8 \mathrm{~nm}^{2}$, and liquid-condensed state II between $\pi=20$ and $38 \mathrm{mN} / \mathrm{m}$, i.e., $A=0.8$ to $0.5 \mathrm{~nm}^{2}$, with a pronounced transition in between (Fig. 1a, curve 3 ). The significant difference between the $\pi-A$ isotherm of the dye on $\mathrm{Hg}\left(\mathrm{ClO}_{4}\right)_{2}$ and those on other salts as well as on water is a "first hint" of the specific interaction (complex formation) between the macrocycle and $\mathrm{Hg}^{2+}$ ions. Such complex formation and consequently enhanced repulsion of the positively charged molecules in this monolayer is a reasonable explanation of the pronounced increase (about $30 \%$ ) of area per dye molecule in the liquid-expanded state in the presence of $\mathrm{Hg}^{2+}$ as compared to other salts or water. The $\pi-A$ isotherm obtained with $\mathrm{AgClO}_{4}$ (not shown here) is similar to that on water up to $\pi=30 \mathrm{mN} / \mathrm{m}$ and more condensed as compared to previously studied styryl dyes [13].

Additional information is obtained from the $\Delta V-A$ isotherms shown in Fig. 1b. The potential values for dye monolayer on water are increasing gradually in the whole range of dye monolayer compression (Fig. 1b, curve 1). This may be due to a continuous chromophore tilting upon dye monolayer compression on water. In contrast, a significant and sharp increase of the potential values for the dye monolayer is observed on $1 \mathrm{mM}$ aqueous solutions of the salts studied here. For example, the surface potential reaches values (about $800 \mathrm{mV}$ ) clearly more positive in presence of $\mathrm{KClO}_{4}$ (Fig. 1b, dashed curve 2) as compared to water (about $380 \mathrm{mV}$, Fig. 1b, curve 1). A remarkable similarity of the $\Delta V-A$ isotherms on $\mathrm{Pb}\left(\mathrm{ClO}_{4}\right)_{2}$ (Fig. $1 \mathrm{~b}$, curve 4) and $\mathrm{KClO}_{4}$ is found (same as for their $\pi-A$ isotherms) indicating nonspecific interaction between dye and these salts. The similarity of $\Delta V-A$ isotherms for dye monolayer on these salts and $1 \mathrm{mM} \mathrm{HClO}_{4}$ (data not shown here) is additional evidence for this interpretation. The $\Delta V-A$ isotherm on the $\mathrm{Hg}^{2+}$ (Fig. 1b, curve 3) and $\mathrm{Ag}^{+}$(not shown) salt solution with sharp increase of about $400 \mathrm{mV}$ differs considerably from those of water (gradual increase on about $380 \mathrm{mV}$ ), $\mathrm{KClO}_{4}$ and $\mathrm{Pb}\left(\mathrm{ClO}_{4}\right)_{2}$ (sharp increase to about $800 \mathrm{mV}$ ) providing evidence for specific complex formation with $\mathrm{Hg}^{2+}$. These features of $\pi-A$ and $\Delta V-A$ isotherms indicate the existence of two types of monolayer structures (due to specific or nonspecific dye-salt interactions) in the case of $\mathrm{Hg}\left(\mathrm{ClO}_{4}\right)_{2}$ and $\mathrm{AgClO}_{4}$ or $\mathrm{KClO}_{4}$ and $\mathrm{Pb}\left(\mathrm{ClO}_{4}\right)_{2}$ solutions, respectively, as compared to pure water as subphase where the dye organization may be assigned as a third type.

\subsection{Reflection spectroscopy}

Important information on chromophore association and orientation as well as dye-cation complexation is gained by measuring reflection spectra of the dye monolayers on distilled water and the various salt solutions. In all cases strong bands are observed in the range of 400-650 nm (Fig. 2). Since the shape of the reflection bands did not vary markedly with dye monolayer compression on water and aqueous salt solutions, only the spectra at $\pi=10 \mathrm{mN} / \mathrm{m}$ are shown in Fig. 2a for water (curve 1) and the $1 \mathrm{mM}$ aqueous solutions of $\mathrm{KClO}_{4}$ (dashed curve 2), $\mathrm{AgClO}_{4}$ (curve 3), and $\mathrm{Pb}\left(\mathrm{ClO}_{4}\right)_{2}$ (curve 4). The reflection maximum on distilled water is at $\lambda_{\max }=442 \mathrm{~nm}$ (Fig. 2a) as compared to $\lambda_{\max }=461 \mathrm{~nm}$ in acetonitrile solution (at $5 \times 10^{-5} \mathrm{M}$ dye concentration). The shift of the maximum may be attributed to the formation of, e.g., head-to-tail dimers of dye $\mathbf{1}$ with the cationic heterocycle interacting with the macrocycle of the neighbor molecule. Such an association could explain the rather small value of the surface potential of dye $\mathbf{1}$ monolayers on water. The intensity of this band in the range of $400-500 \mathrm{~nm}$ is almost 2 times higher than observed for dithiacrown-ether styryl dyes under the same measuring conditions $[13,14]$. The reflection signal normalized for surface density of $\mathbf{1} \Delta R_{\mathrm{n}}=\Delta R \cdot A=0.35 \times 10^{-2} \mathrm{~nm}^{2}$ for water at $\pi=10 \mathrm{mN} / \mathrm{m}$. However, in contrast to the behavior on water, this normalized reflection signal $\Delta R_{\mathrm{n}}$ decreases upon compression (data not shown here) on $1 \mathrm{mM}$ salt solutions, indicating an increasing tilt of the chromophore with respect to the water surface with increasing surface pressure.

In the presence of $1 \mathrm{mM} \mathrm{KClO}_{4}$ (Fig. 2a, dashed curve 2) or $\mathrm{Pb}\left(\mathrm{ClO}_{4}\right)_{2}$ (Fig. 2a, curve 4) in the aqueous subphase, the spectrum is quite different from that on water. A broad band 

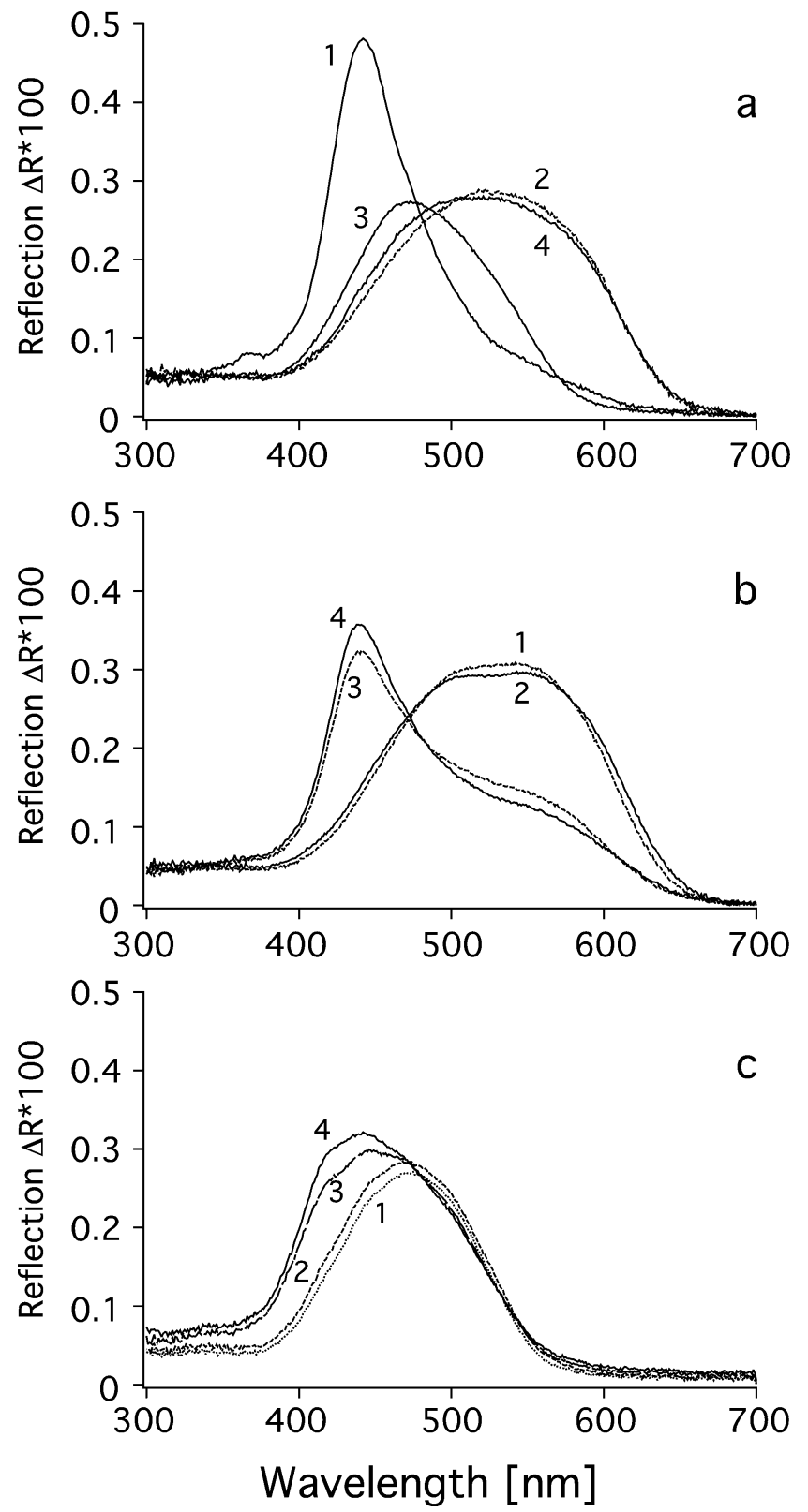

Fig. 2. Reflection spectra of monolayers of the crown ether dye 1: (a) at a surface pressure of $10 \mathrm{mN} / \mathrm{m}$ on water (curve 1) and on $1 \mathrm{mM}$ aqueous solutions of $\mathrm{KClO}_{4}$ (dashed, 2), $\mathrm{AgClO}_{4}$ (3) and $\mathrm{Pb}\left(\mathrm{ClO}_{4}\right)_{2}$ (4); (b) on $1 \mathrm{mM}(1,2)$ and $1 \mu \mathrm{M}(3,4) \mathrm{HClO}_{4}$ at a surface pressure of $10 \mathrm{mN} / \mathrm{m}$ $(1,3)$ and $20 \mathrm{mN} / \mathrm{m}(2,4)$; (c) on $1 \mathrm{mM} \mathrm{Hg}\left(\mathrm{ClO}_{4}\right)_{2}$ at a surface pressure of $1 \mathrm{mN} / \mathrm{m}$ (dotted, 1), $10 \mathrm{mN} / \mathrm{m}$ (dashed, 2), $20 \mathrm{mN} / \mathrm{m}$ (dashed-dotted, 3), and $30 \mathrm{mN} / \mathrm{m}$ (solid curve, 4 ).

with FWHM about $173 \mathrm{~nm}$ and maximum at $\lambda_{\max }=522 \mathrm{~nm}$ is observed in both cases. This may be attributed to the presence of two species, one being the dye 1 monomer and the second with the shift to larger wavelengths a particular associate, whose organization is due to nonspecific interaction with $\mathrm{ClO}_{4}^{-}$. This conclusion is supported by the fact, that almost the same reflection spectra have been obtained for dye monolayers on $1 \mathrm{mM} \mathrm{HClO}_{4}$ (Fig. $2 \mathrm{~b}$, curves 1 and 2). At very low $\mathrm{HClO}_{4}$ concentrations $(1 \mu \mathrm{M})$ in the aqueous subphase, two bands are observed (Fig. 2b, curves 3 and 4), one band with the maximum similar to water, and the second close to that on $1 \mathrm{mM} \mathrm{HClO}_{4}$ (Fig. 2b), as well as on $1 \mathrm{mM} \mathrm{KClO}_{4}$ or $\mathrm{Pb}\left(\mathrm{ClO}_{4}\right)_{2}$ (Fig. 2a). In the case of $\mathrm{AgClO}_{4}$ (Fig. 2a, curve 3) the band maximum is shifted to $\lambda_{\max }=474 \mathrm{~nm}$ and a narrowing of the band is observed $(\mathrm{FWHM}=121 \mathrm{~nm})$ as compared to $\mathrm{KClO}_{4}$, indicating complex formation of the dye with $\mathrm{Ag}^{+}$ions. In acetonitrile solution, complex formation of 1 with $\mathrm{Ag}^{+}$has been observed spectroscopically (data not shown).

In the presence of $\mathrm{Hg}\left(\mathrm{ClO}_{4}\right)_{2}$ in the aqueous subphase (Fig. 2c), the reflection spectrum of dye monolayers at $\pi=$ $10 \mathrm{mN} / \mathrm{m}$ (Fig. 2c, dashed curve 2) has relatively broad band $(\mathrm{FWHM}=115 \mathrm{~nm})$ with $\lambda_{\max }=470 \mathrm{~nm}$ resembling that on $\mathrm{AgClO}_{4}$. However, in contrast to $\mathrm{AgClO}_{4}$ as well as water and other salts, in the presence of $\mathrm{Hg}\left(\mathrm{ClO}_{4}\right)_{2}$ the band maximum shifts upon dye monolayer compression to $\lambda_{\max }=442 \mathrm{~nm}$ at $\pi=30 \mathrm{mN} / \mathrm{m}$, and a small shoulder is observed at $\lambda=420 \mathrm{~nm}$ (Fig. 2c, solid curve 4). This is additional evidence for the strong and specific complex formation between dye and $\mathrm{Hg}^{2+}$. In acetonitrile solution, the dye$\mathrm{Hg}^{2+}$ complex has band maximum at $\lambda_{\max }=441 \mathrm{~nm}$ (i.e., close to that in the monolayer at high surface pressures), but without pronounced shoulder. Upon dye monolayer compression on $\mathrm{Hg}\left(\mathrm{ClO}_{4}\right)_{2}$, the normalized reflection intensity decreases indicating an increase of the chromophore tilt.

\subsection{Monolayer topography}

The different organization of dye $\mathbf{1}$ in monolayers at $\pi=10 \mathrm{mN} / \mathrm{m}$ on the different subphases studied here is also expressed in the topography as seen by BAM; see Fig. 3. On water very small domains are just visible (Fig. 3a). BAM images of the monolayer on $\mathrm{KClO}_{4}$ (Fig. 3b) and $\mathrm{Pb}\left(\mathrm{ClO}_{4}\right)_{2}$ (Fig. 3c) are almost identical, but differ from those on water. The domains dominating the images show strong contrast presumably due to different azimuth with respect to the incident p-polarized light. The remarkable similarity of the topography is strong evidence for a similar molecular organization in these monolayers. Finally, the monolayer on $\mathrm{AgClO}_{4}$ (not shown) and $\mathrm{Hg}\left(\mathrm{ClO}_{4}\right)_{2}$, respectively, appears homogeneous (Fig. 3d, the interference fringes seen in the image result from dust particles on the optical components). This behavior is additional evidence for a specific interaction of dye 1 with $\mathrm{Ag}^{+}$and $\mathrm{Hg}^{2+}$, respectively, as compared to $\mathrm{KClO}_{4}$ and $\mathrm{Pb}\left(\mathrm{ClO}_{4}\right)_{2}$.

\subsection{Photoisomerization}

The dye monolayers on water (data not shown here) showed a sharp decrease of reflection signal at the maximum of the band at $440 \mathrm{~nm}$ within about 1 min upon illumination with light of wavelength $438 \mathrm{~nm}$, i.e., close to the band maximum. The reflection $\Delta R$ has not become constant (steady state not reached) when the light has been switched off. No (or negligible) increase of $\Delta R$ has subsequently been observed in the dark. Similar irreversible changes of 

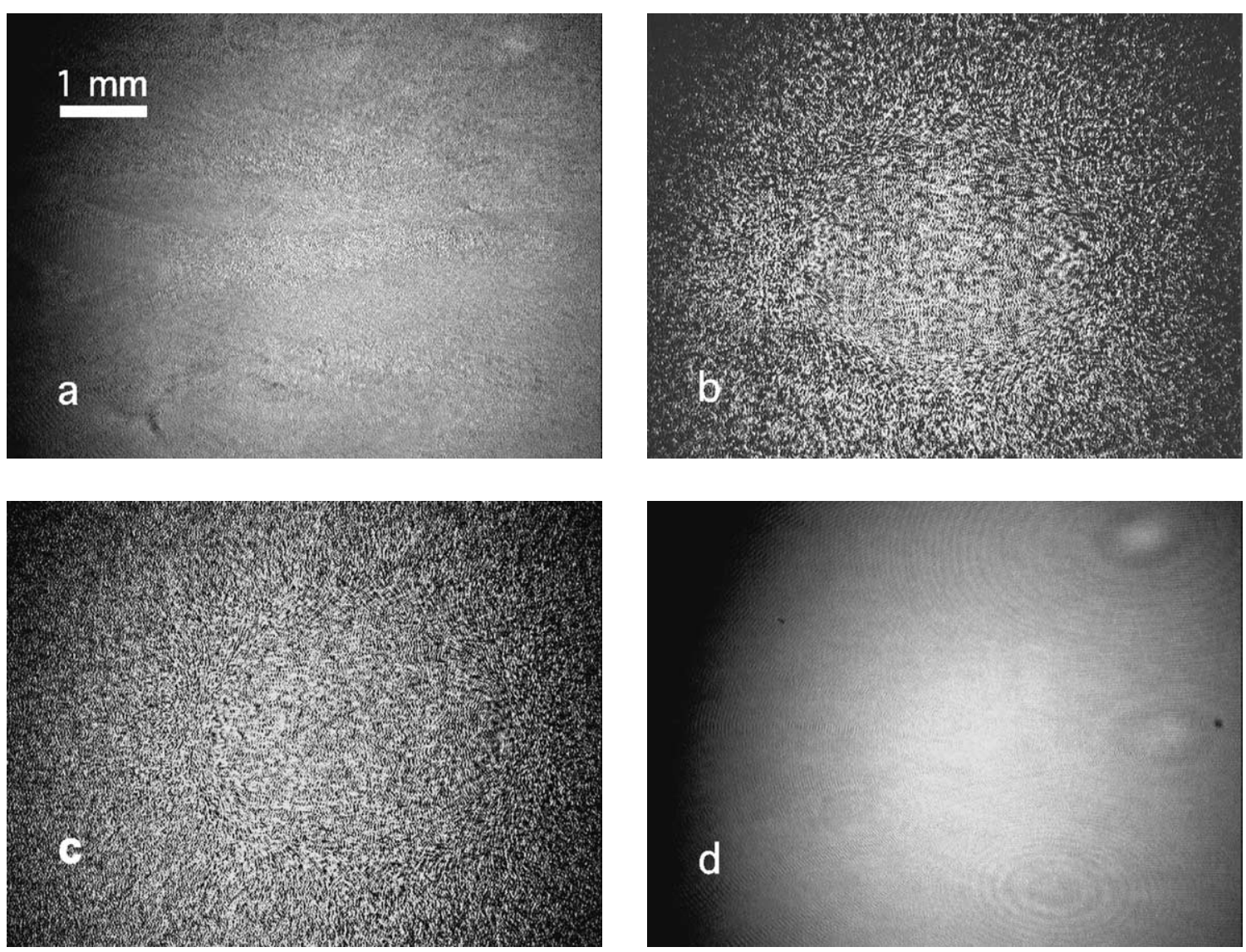

Fig. 3. BAM images of the crown-ether dye 1 monolayers on water (a) and $1 \mathrm{mM}$ solutions of $\left.\mathrm{KClO}_{4}(\mathrm{~b}), \mathrm{Pb}_{(\mathrm{ClO}}\right)_{2}(\mathrm{c}), \operatorname{and} \mathrm{Hg}\left(\mathrm{ClO}_{4}\right)_{2}(\mathrm{~d})$.

$\Delta R$ have been observed for all studied salts, with only one exception. In the presence of $1 \mathrm{mM} \mathrm{Hg}\left(\mathrm{ClO}_{4}\right)_{2}$ the photoinduced changes of $\Delta R$ are reversible (steady state has been reached) since $\Delta R$ increases almost to the initial values after the light has been switched off. These results are the first indication of the interplay of ionoselective and photosensitive properties of the novel dye $\mathbf{1}$ in monolayers.

\section{Summary}

The novel amphiphilic benzodithia-18-crown- 6 butadienyl dye $\mathbf{1}$ forms stable monolayers on water and various $1 \mathrm{mM}$ aqueous salt solutions. A variety of associates as well as complex formation with $\mathrm{Hg}^{2+}$ and $\mathrm{Ag}^{+}$has been observed. In the case of $\mathrm{K}^{+}$no complexes were found neither in the monolayer nor in solution. To our surprise, $\mathrm{Pb}^{2+}$ ions that clearly show complex formation in acetonitrile solution are not interacting with the macrocycle in the monolayer; however, nonspecific interactions of the anion $\mathrm{ClO}_{4}^{-}$cause a behavior different from that on water in the presence of both $\mathrm{KClO}_{4}$ and $\mathrm{Pb}\left(\mathrm{ClO}_{4}\right)_{2}$. Reversible photoisomerization of dye $\mathbf{1}$ monolayers has been observed in the presence of $1 \mathrm{mM} \mathrm{Hg}^{2+}$ in the aqueous subphase only. We anticipate that the approach described here will be useful for the construction of functional supramolecular systems.

\section{Acknowledgments}

The authors are grateful to Dr. T.M. Jovin for fruitful discussions and to W. Zeiss (Max-Planck-Institut für biophysikalische Chemie, Göttingen, Germany) for technical assistance. Some parts of this work have been supported by grants from the Russian Foundation for Basic Research (Russia, Projects 00-03-33238, 00-03-32898, 00-03-32159, 01-03-32474, 02-03-04003), INTAS (Project 2001-0267), the Alexander von Humboldt-Stiftung (Germany) and the Deutsche Forschungsgemeinschaft (Germany, Project 436 RUS 113/686).

\section{References}

[1] J.-M. Lehn, Supramolecular Chemistry, VCH, Weinheim, 1995.

[2] S.P. Gromov, M.V. Alfimov, Russ. Chem. Bull. (Engl. Trans.) 46 (1997) 611.

[3] S.Y. Zaitsev, V.V. Lutchenko, V.P. Zubov, Bioorgan. Chem. (Russ.) 9 (1983) 567.

[4] I.K. Lednev, M.C. Petty, Adv. Mater. 8 (1996) 615.

[5] H. Huesmann, J. Maack, D. Möbius, J.F. Biernat, Sensors Actuators B 29 (1995) 148.

[6] L.M. Goldenberg, J.F. Biernat, M.C. Petty, Langmuir 14 (1998) 1236.

[7] I. Zawisza, R. Bilewicz, E. Luboch, J.F. Biernat, Supramolec. Chem. 12 (2000) 123. 
[8] I. Zawisza, R. Bilewicz, M.R. Moncelli, R. Guidelli, J. Electroanalyt. Chem. 509 (2001) 31.

[9] S.Y. Zaitsev, S.P. Gromov, O.A. Fedorova, E.A. Baryshnikova, V.P. Vereschetin, W. Zeiß, H. Huesmann, M.V. Alfimov, D. Möbius, Colloids Surf. A 131 (1998) 325.

[10] S.Y. Zaitsev, V.P. Vereschetin, S.P. Gromov, O.A. Fedorova, M.V. Alfimov, H. Huesmann, D. Möbius, Supramol. Sci. 4 (1997) 519.

[11] S.Y. Zaitsev, V.P. Vereschetin, E.A. Baryshnikova, S.P. Gromov, O.A. Fedorova, M.V. Alfimov, H. Huesmann, D. Möbius, Thin Solid Films 329 (1998) 821.

[12] S.Y. Zaitsev, T.I. Sergeeva, E.A. Baryshnikova, W. Zeiss, D. Möbius, O.V. Yescheulova, S.P. Gromov, O.A. Fedorova, M.V. Alfimov, Mater. Sci. Eng. C 8-9 (1999) 469.
[13] S.Y. Zaitsev, E.A. Baryshnikova, T.I. Sergeeva, S.P. Gromov, O.A. Fedorova, O.V. Yescheoulova, M.A. Alfimov, S. Hacke, W. Zeiss, D. Möbius, Colloids Surf. 171 (2000) 283.

[14] S.Y. Zaitsev, E.A. Baryshnikova, T.I. Sergeeva, S.P. Gromov, O.A. Fedorova, O.V. Yescheoulova, M.V. Alfimov, S. Hacke, W. Zeiss, D. Möbius, Thin Solid Films 372 (2000) 230.

[15] S.P. Gromov, E.N. Ushakov, O.A. Fedorova, V.A. Soldatenkova, M.V. Alfimov, Russ. Chem. Bull. (Engl. Trans.) 46 (1997) 1143.

[16] A.I. Vedernikov, S.P. Gromov, Synthesis 6 (2001) 889.

[17] D. Hönig, G.A. Overbeck, D. Möbius, Adv. Mater. 4 (1992) 419.

[18] M. Orrit, D. Möbius, U. Lehmann, H. Meyer, J. Chem. Phys. 85 (1986) 4966.

[19] R.C. Ahuja, P.-L. Caruso, D. Möbius, Thin Solid Films 242 (1994) 195. 